\title{
A Conceptual Framework for Work-Applied Learning: Developing Managers as Practitioner Researchers
}

\section{Introduction}

In the twenty-first century, increasing globalisation, complexity and turbulence across the globe provide ample evidence of the need for a new paradigm of learning and development at work (Bawden, in press). This paradigm is needed as an alternative or complement to, and not in competition with, the formal education system (Zuber-Skerritt \& Teare, 2013). It is rooted in an understanding of learning that is different from most other learning paradigms and is particularly suited for the present and future time. The difference is its epistemology, informed by various theories of learning, as we explain in this article. This is not a research paper or case study but a conceptual paper as defined by Emerald guidelines: "These [conceptual] papers will not be based on research but will develop hypotheses. The papers are likely to be discursive and will cover philosophical discussions and comparative studies of others' work and thinking." (http://www.emeraldgrouppublishing.com/authors/guides/write/abstracts.htm?part=2 \#sthash.7LVsPLvh.dpuf). The present conceptual paper is based on our personal and professional experience of conducting, facilitating and evaluating work-applied action learning programs and participatory action research projects. It is informed by our reflections on these experiences and by the most recent literature since the seminal work of Zuber-Skerritt (2011). Here our aim is to introduce a conceptual framework for Work-Applied Learning (WAL) that provides a basis for the development of managers and other professionals as lifelong learners and practitioner researchers - through reflective practice, action research, action learning and action leadership, for positive organisational change.

This article proposes Work Applied Learning (WAL) as a model (Abraham, 2015) for developing managers as practitioner researchers (Dahlberg and McCraig, 2010; Drake and Heath, 2011; Fox, Martin and Green, 2007). We define the term practitioner researchers as managers or other professionals who conduct research in the workplace to improve the quality of their practice, to engage in organisational improvement or other change, to create knowledge, and to make the results of their research public so that their work can be scrutinised, and can inform the understandings of others, e.g., through oral presentations, written company reports, in-house papers, newsletters, dissertations or theses, articles or books. We explain how the phenomenological paradigm of knowledge creation and relevant supporting theories of learning and knowing can be applied, adopted or adapted to develop and facilitate leadership and management skills in students/managers. It can do so by promoting self-directed learning and publication of findings through collaborative, qualitative action research, and reflective practice. Understanding this conceptual framework is vital for both understanding and most effectively using the model of WAL in organisations or other circumstances, at a systemic level (Burns, 2007) and in a sustainable way.

Abraham's (2015) model of Work-Applied Learning (WAL) is clearly defined in the next section. However, we recognise that to maximise the concept's 
potential for individual learning, team learning, organisational learning, community learning, knowledge management, work-based learning and change, it needs to be placed in a broader methodological and philosophical context, as explained in the main part of this article ('the WAL paradigm' and 'theories of knowing and learning'). Here we aim to strengthen the conceptual framework for the WAL model by placing it in terms of theory, pedagogy and methodology. Abraham designed the WAL model as an extension of Work-Based Learning (WBL) through fusing Action Learning (Revans, 1971, 1982, 1991, 1998, 2006) and Action Research (Lewin, 1926, 1948, 1951) with reflective practice (Knott and Scragg, 2011; Moon, 2006; Taylor, 2000) and case study methodology (Yin, 2013). The utility of these four complementary approaches for enhancing the WBL model became evident through practice. However, the meaning of the 'action' terms has changed over time. As Abraham (2015, p. 6) points out:

The original concepts first voiced by Revans and Lewin have not stood the test of time intact and inviolate. Rather, opinions about what Action Learning and Action Research mean and how to implement them are many and varied. Consequently, every group that wants to undertake an Action Learning project or an Action Research program must consider these various opinions and then decide what form of research or learning is appropriate for its needs.

Zuber-Skerritt's (2002a, b) definitions of Action Learning and Action Research also vary slightly from those of Abraham's but what they have in common are the paradigm, theories, methods and processes of learning, development, leadership and change. From this common ground, we decided to provide a conceptual framework for the WAL model since we believe this model has particular currency for knowledge creation in contemporary workplaces wherever they may be. Offering a carefully considered conceptual framework for the WAL model enhances the capacity of model users to apply, adapt and further develop its conceptual underlay and to enhance conceptual and practical knowledge creation and learning through this process. The WAL model is used successfully in the Australian Institute of Business (AIB) and in the Global Centre for Work-Applied Learning (GCWAL) in Adelaide, both of which were founded by Selva Abraham, in partnership with other organisations. AIB is the largest private business school in Australia that is government accredited from Bachelor to Doctoral levels, including $\mathrm{PhD}$.

In this article we first summarise and discuss Abraham's (2015) WAL model. Second, we explain the key concepts that characterise it. Third, we offer a conceptual framework for the model drawing from related theoretical thinking that includes aspects of phenomenology (Smith, 2013; Zohavi, 2003), experiential learning theory (Biggs, 2005; Boud, Keogh and Walker, 1985; Kolb, 1984), strengths-based theory (Harvey, 2014; McCashen, 2005; Saleebey, 2005), grounded theory (Charmaz, 2006; Corbin and Strauss, 2013), and critical theory (Bhaskar, 2008; Carr and Kemmis, 1986; Kemmis, McTaggart and Nixon, 2014). In clarifying the conceptual framework of WAL, we provide a theoretical, educational and methodological rationalisation of the WAL model that further develops its utility for researchers' and practitioners' applications.

\section{The Work-Applied Learning (WAL) Model}


Work-Applied Learning (WAL) incorporates Work-Based Learning (WBL), while grounded in a fusion of Action Research method and Action Learning process (ARAL). WBL focuses on learning in the workplace by individuals or teams to create and apply knowledge in the workplace. The WAL model extends the process by using the ARAL approach to create, in a more systematic and conscious way, organisational learning, knowledge management and organisational change. The ARAL approach entails a cyclical process as practitioner researchers and their teams plan, act, observe, reflect, evaluate and validate their work-based projects through the action research cycles of WAL. Figure 1 shows the cyclical nature of WAL from individual learning to team learning to organisational learning and knowledge management eventuating in organisational change.

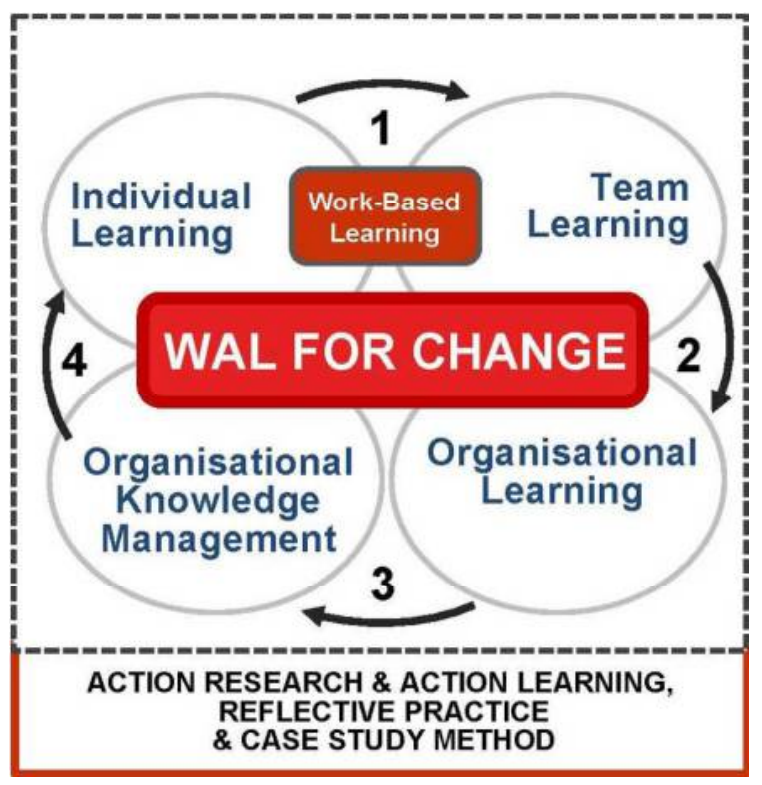

Figure 1. Cyclical nature of work-applied learning (WAL)

The WAL program as explained by Abraham (2015, pp. 1-36; 177-179) begins with a substantial and often complex problem, issue or concern in the workplace that has not been solved before, that is of concern to the CEO, and that is to be addressed by senior managers in collaboration with other employees. This problem-solving team learns from and with each other (i.e., action learning); they proceed through several cycles of systematic inquiry using cycles of planning, acting, observing and reflecting (i.e., action research) while applying their learning, knowledge, critical thinking and other skills to their project work. They then monitor, evaluate, reflect upon and validate their findings collaboratively and in doing so they ascertain the outcomes of the WAL program. These are project outcomes, process outcomes, learning outcomes and sustainable transformation, all of which constitute a valuable return on investment (ROI) within the organisation. The WAL program offers an effective way of management learning at the individual, team and organisational levels because it is systematic, systemic and work/life based and leads to organisational knowledge creation. It recognises, uses and appreciates workplace 
learning and its utility, not just for theoretical and practical knowledge creation and organisational improvement, but also for improving the workplace/life experiences of all in the organisation as a learning organisation (Senge, 1990).

Abraham (2015, pp. 7-9) identifies 12 general characteristics of action research that should emerge in WAL. It has problem focus, action orientation, cyclical process, collaboration, ethical practice, group facilitation, creative thinking, learning and re-education, and it is naturalistic (non-positivist, qualitative case studies), emancipatory, normative (but modified/changed during the AR process) and scientific (rigour).

In recent years Zuber-Skerritt has developed an approach she has called Participatory Action Learning and Action Research (PALAR), which particularly highlights the participatory nature of action learning and action research. She has summarised (Zuber-Skerritt, 2011) the seven C's of PALAR that somewhat overlap with the characteristics of WAL that Abraham identified independently: Communication, Collaboration, Commitment, Competence, Compromise, Critical reflection, and Coaching. All of these contribute to Character building of the manager as action researcher, who is holistic, ethical, responsible, democratic, caring and loving, i.e., the global citizen required for peace and social justice in this twenty-first century.

A WAL program is conducted by members of a workplace organisation who share an interest in collectively identifying and solving a shared workplace concern. Managers form an action research (AR) group to establish and conduct the WAL program, which includes several action research cycles and normally six phases within each cycle. These phases constitute:

1. Action research (AR) group meetings on a regular basis as face-to-face or webconference meetings, where managers share views, questions and experiences, discuss and reflect on the outcomes of their projects, processes and learning;

2. Knowledge workshop phase of one to four days duration, depending on managers' needs and demands of the organisation, focusing on business concepts (e.g., strategy, marketing, finance, human resources, operations, and leadership), introduced by a Facilitative Tutor, supplemented by distance learning and reading materials and an online library, and concluding with each manager's draft plan for a change project, including departmental projects;

3. Work-based phase where managers in their workplace are equipped as facilitative leaders to guide their departmental learning teams in planning and implementing their work-based projects;

4. Joint observations and reflections at the end of each work-based phase, with a Facilitative Consultant to monitor progress and to provide assistance managers might need in the next cycle;

5. Evaluation of cycles by the managers, the Facilitative Consultant and other AR group members, in an evaluative meeting where they analyse performance outcomes and evaluate outcomes of the projects, processes and learning; and

6. Validation of the WAL program at the end of every two cycles by the AR group and its key stakeholders, with managers' report presentations, feedback, and possible changes to the program if seen to be useful. 
This systematic and systemic WAL model seeks to maximise the organisational and personal benefits of a cyclical work-applied learning experience for managers at an organisational level. It is future oriented and highly relevant for developing the skills and knowledge that Jackson (2011) and Trilling and Fadel (2009) have identified as vital for the twenty-first century. However, cultivating these skills and knowledge in the workplace requires a revised paradigm of learning and development that fosters self-directed, lifelong action learning, and creative and innovative thinking 'outside the box'. It must appreciate and generate organisational capacity to achieve the type of development essential for succeeding in this rapidly changing world, i.e., development that addresses totally new and complex problems collaboratively and effectively, and produces sustainable outcomes. In the next section we clarify the key concepts pertaining to the WAL model before offering a conceptual framework for this model.

\section{Key Concepts of WAL}

As mentioned, Abraham's (2015) model of Work-Applied Learning integrates the concepts of Work-Based Learning (WBL) with action research and action learning (ARAL). It includes reflective practice, lifelong learning and action leadership. It is useful to re-evaluate and re-conceptualise the WAL model's concepts, independently and in their syntheses, to maximise the model's utility for addressing twenty-first century problems. These so-called 'wicked problems' (Dick, 2012) entail increasing complexity, ambiguity, turbulence and tension among different values and beliefs. Since WAL is conceived as work-applied action learning/research/leadership, it is a philosophy and methodology of change and is therefore valuable for sustainable learning and change, including personal, organisational, community and environmental change. This capacity is especially pertinent in present times when changes in the global environment serve to multiply these so-called 'wicked problems' across all aspects of life. From here we briefly summarise the key concepts of WAL: WBL, ARAL, reflective practice, organisational learning, lifelong learning, and action leadership.

\section{Work-Based Learning (WBL)}

WBL refers to programs where the learning that takes place is primarily at and through work, for the purposes of work. Gibbs and Garnett (2007, p. 411) define work-based learning as:

A learning process which focuses university level critical thinking upon work (paid or unpaid), in order to facilitate the recognition, acquisition and application of individual and collective knowledge, skills and abilities, to achieve specific outcomes of significance to the learner, their work and the university.

Garnett (2012) explains that in the UK, work-based learning is often associated with lower level learning, but it can also span all the levels of higher education from certificate through to doctoral level. Work-based learning at higher education level can range from a component of a course unit to entire qualifications and it can be used to help young people integrate work and learning to help them enter 
employment or it can be the vehicle mature students choose to facilitate part of their continuing professional development. Boud and Solomon $(2001$, p. 1) identify a range of distinctive features of higher-level work-based learning:

- Work-based learning is a partnership between an external organisation and an educational institution specifically established to foster learning;

- Learners are employees or have some contractual relationship with the external organisation and negotiate learning plans approved by the educational institution and the organisation;

- The learning plans are derived from the needs of the workplace and of the learner, rather than being predetermined by a subject disciplinary curriculum;

- The starting point and level of the negotiated learning program is established after a structured review and evaluation of the current learning of the individual;

- Work-based learning projects that meet the needs of the learner and the organisation are a significant element of the program; and

- Assessment of the learning outcomes of the negotiated program is carried out with reference to a transdisciplinary framework of standards and levels.

\section{Action Research and Action Learning (ARAL)}

Lewin's (1926, 1948, 1951) concept of Action Research and Revans' (1982) concept of Action Learning are similar in some respects as both are problem-focused, actionorientated and utilise group dynamics. However, they differ in a number of major respects. Action research (AR) includes action learning (AL), but - like any other approach to research - action research is more rigorous, systematic and scrutinised than action learning, and it is always made public in oral and/or written form. While Ortrun has integrated the two as $A L A R$ (starting with AL and gradually developing skills for AR), Selva's focus in WAL is more on AR for project assessment and evaluation, and using AL sets for personal, professional and organisation development, hence naming this integration $A R A L$. The effect of both ALAR and ARAL is the same.

\section{Reflective Practice}

Being a 'reflective practitioner' or a member of a 'reflective practice' means one engages in a continuous search for knowledge - both propositional and theoretical (knowing that ...) and knowledge derived from practice (knowing-in-action or knowledge-in-use, i.e., tacit, spontaneous knowledge and thinking on one's feet). Action learning as a reflective process is iterative and continuing - it has no end point. Schön $(1983,1987)$ distinguishes between 'reflection-in-action' (thinking while in the process of doing something) and 'reflection-on-action' (reflecting after the event on what one did). The latter encourages reflective learning as well as critically reflective learning. More recently, reflective practice has been extended in theory and practice (Greenwood, 2012; Knott and Scragg, 2011; Moon, 2006; Taylor, 2000).

\section{Organisational Learning}

Organisational learning is a process of creating, retaining and transferring knowledge throughout the organisation for improving practice at the individual, 
group/team, organisational and inter-organisational levels, and for continuous positive change and development. Like individual learning, organisational learning is about the construction and accessibility of meaning, but it is most effective in a culture that fosters collaborative work. Organisational learning occurs in 'learning organisations' that Senge (1990, p. 3) explains as:

... organizations where people continually expand the capacity to produce the results they truly desire, where new and expansive patterns of thinking are nurtured, where collective aspirations are set free, and where people are continually learning how to learn.

In other words, a learning organisation fosters a work environment and a culture that encourage members to draw from knowledge within the organisation and to think critically and creatively. The WAL concept understands learning as an ongoing, creative and lifelong process, one that adapts and transforms in response to the needs and aspirations of people inside and outside the organisation.

\section{Lifelong Learning}

Sheehan (2001, p. xi) in his Foreword to the Kluwer International Handbook of Lifelong Learning offers one of the most comprehensive understandings of lifelong learning:

Lifelong Learning is a concept that is critically important to all educators, for it expresses the importance and relevance of learning at every stage of our development. The concept is equally relevant to members of our society at all stages of their life-span - as young children, maturing youth, adults, and as older persons. Further, it affects national governments, industry, information agencies and nearly every kind of institution of learning.

So important is the concept, it should be seen by all of us as representing a new philosophy of education and training, one that aims to facilitate a coherent set of links and pathways between work, school and education, and [to] recognise the necessity for government to give incentives to industry and their employees so they can truly "invest" in lifelong learning. It is also a concept that is premised on the understanding of a learning society in which everyone, independent of race, creed or gender, is entitled to quality learning that is truly excellent.

However, there are many different concepts and conceptions of lifelong learning (Aspin, Chapman, Hatton and Sawano, 2001; Jackson, 2011; Jarvis, 2001; ZuberSkerritt and Teare, 2013). Billet (2010) warns of the perils of confusing lifelong learning with lifelong education. Whilst the former is a personal process, the latter is an institutional process. And although school- or university-based courses may be valuable, the danger is that - as in some literature - the importance and ubiquity of learning experiences outside courses are largely ignored or marginalised, as well as the scholarship of adult learning and development across people's life courses.

In the WAL model of action research cycles explained above, we are able to integrate aspects of lifelong education (through collaborative knowledge workshops and distance education materials) with the participants' lifelong learning processes 
(through work-based projects, AR meetings, using joint observations, reflections, collaborative evaluation and validation).

\section{Action Leadership}

Abraham's (2015) WAL model introduces four roles of facilitative leadership: facilitative training, facilitative tutoring, facilitative leading, and facilitative consulting. We see that the key to all four is action leadership. WAL is the ideal model for developing action leadership among managers. Cantwell (2015) draws from his extensive military experience in claiming that leadership in action is about emotional connections, trust and being authentic. Zuber-Skerritt (2011, p. 231) draws from her experience as an academic staff developer and consultant for over 40 years:

Action leadership is a new concept of leadership that involves action, concern and responsibility for others, rather than a position of power and control over them. This kind of leadership is not reserved for an elite in power or an hierarchical position, but it is possible to achieve for all who are willing and capable to develop a capacity, knowledge, skills, attitude and democratic values of freedom, equality and fraternity for all humankind. Significant action leaders know, go and show the way and take joy in helping others succeed.

Action leadership - conceived as primus inter pares (first among equals) - can be developed through WAL. Action leaders can facilitate within their ARAL group the important knowledge and skills for vision and team building; identifying issues, strengths and weaknesses; and strategic action planning, implementation and evaluation, using critical reflection at every stage. Action leaders see the big picture, but they need to develop leaders around them (Maxwell, 1995) to achieve shared, democratic action leadership. In summary, WAL:

- is learner-centred and work-based (through project work);

- is specific to the needs of an organisation;

- uses ARAL and reflective practice;

- applies directly to managers' real life/work;

- is lifelong (pursued continuously); and

- fosters non-hierarchical action leadership.

WAL when used effectively improves the quality of life/work for all in a workplace organisation and, as a consequence, for many beyond. WAL programs are effective for unlocking human potential and vitally, their outcomes are sustainable.

\section{Conceptual Framework for the WAL Model}

To explain the WAL model, we find it most useful to adapt the conceptual framework for WAL from Zuber-Skerritt, Wood and Louw's (2015) framework for Participatory Action Learning and Action Research (PALAR). The conceptual framework of WAL, like that of its close relative PALAR, is informed by "a participatory paradigm of an engaged scholarship in higher education". ${ }^{1}$ Because this article is to introduce WAL as a new concept, our discussion here includes only those aspects of epistemological theories that explain and validate use of the WAL 
model for workplace learning and problem solving and does not need to critically analyse these theories. 


\section{The WAL paradigm}

The WAL paradigm is congruent with the paradigm of Participatory Action Learning and Action research (PALAR) explained in Zuber-Skerritt et al. (2015). Traditionally, it has been assumed that scientists create theoretical knowledge in their specialist disciplines, and that practitioners then apply this knowledge in their practice. In the alternative paradigm of WAL and PALAR, we accept that there are other kinds of knowledge beyond theoretical and practical, including emotional, spiritual, local and indigenous knowledges, and so there are other sources of knowledge beyond scientific testing. WAL accepts that everyone of sound mind can learn how to (1) identify a complex, practical problem that needs to be researched and solved urgently, (2) plan a project collaboratively in a team of like-minded people who are passionate about inquiring into an issue, (3) observe the action, (4) reflect on the results of the research, (5) think critically through the research process to identify conceptual and practical knowledge, and (6) re-plan for future improved practice or change. This process is an interaction and integration of action and research into 'action research'. It is not conducted by a specialist researcher, but by practitioner researchers who are involved in the action as participant observers, critical thinkers/reflectors and co-researchers who join 'the tribe' (Godin, 2008), as in anthropology. This kind of research is different from traditional, disciplinary or large-scale social science research. It focuses on small groups at a time, and requires predominantly qualitative rather than quantitative research methods, and a considered understanding of phenomenological research in the participatory paradigm.

\section{Theories of knowing and learning}

We believe the WAL model is best explained by aspects of selected epistemological theories integrated in a conceptual framework. These theories are predominantly (1) phenomenology, (2) experiential learning theory, (3) strengths-based theory, (4) grounded theory, and (5) critical theory/realism. These and theories like them are fundamental for understanding the WAL model and related practices of workapplied, lifelong learning through action learning, action research, and action leadership.

\section{Phenomenology}

Phenomenology is a philosophy and a research tradition that focuses on phenomena as they appear in the natural, experienced human world. Researchers study how this world actually appears to people or how people experience and conceive the world around them. We refer readers to Van Manen's (2014) comprehensive work on the 'phenomenology of practice' because it presents key phenomenological ideas and methodological issues of phenomenological reflection and writing in professional contexts.

Phenomenology is the overall paradigm that guides us in WAL. According to Kuhn (1970, p. 175): "A paradigm is what the members of a scientific community share ... it stands for the entire constellation of beliefs, values, techniques, and so on shared by the members of a given community". Here our community consists of (1) scholars as practitioner researchers interested in improving/changing their praxis of learning, teaching, research and leadership, and (2) their work colleagues and 
partners in other institutions, communities, and organisations, in business, industry and government, locally and globally.

From this paradigm we argue that the human and social sciences require methodologies and methods different from those of the natural sciences because the nature, behaviour and views of humankind constitute a complex whole that cannot

be observed objectively, or in parts, by outside researchers. Observations of humankind are not neutral, objective or value free; they are subjective because choices that guided the observation and interpretations depend on the observers' theoretical framework and values. Therefore, 'observers' are 'participants' who are actively involved in the research process (e.g., in choosing who/what to examine, what questions to ask of whom, and in analysing and interpreting data). They seek to make the findings as objective as possible through qualitative methods and triangulation. We argue for a phenomenological approach to WAL through practitioner research into their organisational practice, in order to improve or otherwise change their organisation.

\section{Experiential Learning Theory}

Kolb's (1984) classic experiential learning theory is based on the premise that adults can create knowledge on the basis of their concrete experience. They can observe and reflect on that experience, formulate theoretical or abstract concepts and generalisations, and then test the implications of these concepts in new situations, which provide them with new concrete experience. This theory, envisaging an ongoing lifelong cycle of learning and of creating knowledge, was first developed by Lewin $(1948,1951)$ and extended by Kolb $(1984$, p. 21).

Kolb's experiential learning theory is the cornerstone of WAL because it follows an iterative process of reflection and action. Our reflections on, in, for and through action generate new questions and insights for the next action in our learning and research, and so the cycle continues throughout our life, including in our work and other professional or organisational activities. This approach to experiential and lifelong learning can be facilitated, developed and enhanced through qualitative methods, such as keeping a reflection diary, holding reflection sessions or evaluative discussions with others who are involved, and eliciting feedback from 'critical friends' whose advice we trust.

\section{Strengths-based Theory}

In strengths-based theory, which is informed by other theories such as positive psychology, social change theory, hope theory and motivation theory, it is assumed that every person, group or organisation has strengths and assets that can be built on and further developed in practice and research. This is opposite to the traditional deficit approach where experts observe 'subjects' and identify deficits and then design interventions to solve the problem. This deficit approach often leads to a negative sense of self-confidence, self-esteem and self-efficacy. In strengths-based practice, 'participants' generate strategies and solutions for themselves according to their abilities and for their contexts (McCashen, 2005; Saleebey, 2005).

Harvey (2014) explains the nexus between strengths-based theory/practice and action research, and maintains that the central tenet of strengths-based theory and practice is analogous with that of action research. That is, all stakeholders in a 
project or activity are participants in a process of inquiry, working together as they try to find the best solutions and to develop new knowledge. The strengths-based approach starts with a focus upon the participants' identifiable strengths in order to achieve this critical nexus between problem solving and knowledge creation. What the strengths-based approach and action research have in common is an emphasis on action as a goal and on achieving positive change. This change is likely to be transformative because reflective practice is valued by and inherent to both. Harvey (2014) also shows how each moment of the action research cycle (plan - act observe - reflect) can be strengthened by shared leadership, active listening, providing affirmation, positive reinforcement, acknowledgement of contributions, and autonomy within agreed boundaries (e.g., ground rules and mutual expectations). This theory strongly resonates with the collaborative and positive paradigm of WAL, PALAR and action leadership.

\section{Grounded Theory}

Based on the early theory by Glaser and Strauss (1967), recent reference books such as Bryant and Charmaz (2007), Charmaz (2006), Corbin and Strauss (2013), and Gibson and Hartman (2013) have developed grounded theory in the new, participatory paradigm. Grounded theory provides a theoretical framework for WAL and other methodologies within this paradigm because, as these studies reveal, it has proven that theoretical knowledge can be generated from specific contextual information and data collected within a certain context (e.g., an organisation or community). Information/data collection is an iterative process of alternating and mutually interacting the phases of discovery and subsequent testing or 'sampling of grounded theory'. Zuber-Skerritt (2009, pp. 108-109) explains:

Unlike scientific empirical research aiming to verify 'grand theories' and placing little value on who and what are involved in creating these theories, 'grounded theory' places value on generating meaningful theories, emphasising the process of their creation. While empirical research produces 'etic' theory by an 'outsider' who is seen to be 'uninvolved' in the research process and 'removed' from the object of enquiry, grounded theory is 'emic', informed by an insider view of the people, groups, organisations or cultures being studied. The etic enquirer tries to establish generalisable (nomothetic) laws; the emic enquirer wants to provide knowledge and understanding of a particular, individual (ideographic) case. For the former, generalisations might be statistically purposeful and significant (e.g., in population audits, identifying causes of illness and health, national trends), but often they are not applicable or [are] irrelevant to the individual case and specific group. Action research is directly and exclusively relevant to an individual case and specific group.

Grounded theory derived from data analysis is always an interpretation by researchers through their personal lenses or 'windows to the world' and through their critical and self-critical reflection on the data analysis and action. This is where critical theory is helpful. 


\section{Critical Theory and Critical Realism}

Our critical theory is influenced by the Frankfurt School of Critical Theory (Adorno, 2008; Habermas, 1974, 1978) and by Carr and Kemmis' (1986) seminal work: Becoming Critical: Education, Knowledge and Action Research. In WAL programs or projects, it is important for participants to 'become critical' and self-critical because we aim at sustainable transformational change, whether personal, professional, organisational or community learning and change. As Zuber-Skerritt (2009, p. 111) points out:

This means critique is never taken as a personal attack (destructive), but [is] accepted as a necessary move to bring about organisational improvement, innovation or re-creation (constructive). In action learning programs, participants submit thoughts and ideas about actions to the constructive scrutiny of supportive colleagues as 'critical friends'. We learn from our mistakes and failures as well as from successes. We are not interested merely in changing people and organisations; we want them to grow and learn, and we want to learn ourselves within this process.

Another important principle of critical theory is 'symmetrical communication', grounded in the understanding that everyone in the WAL team regards each other as their equal, no matter what their rank or position. Each member therefore contributes equally, although differently, according to their personal strengths, individual gifts and interests, as in strengths-based theory. Each treats all others with respect, inclusion and having a right of opinion. The shared assumption is that each individual has knowledge, skills and talents in a particular area, which can be identified and used effectively for the common good.

In the English-speaking world, Bhaskar's (2008) critical realism has been influential as a philosophical approach to social and human sciences, especially in regard to social change and to the promotion of human agency and freedom. His work originated from the German tradition of critical theory and dialectics, but developed a special philosophy of critical naturalism that recognises the similarities and differences between natural sciences and social sciences and that the human and social worlds are in a much greater state of flux than those of the physical world. Human and social structures change much more readily than those of organic plants, for example, or non-organic matter. Human agency is made possible by social structures, and individuals who inhabit these social structures are capable of consciously reflecting upon and changing practices that in part are facilitated by social scientific research.

Table 1 is a summary of how each of the theories discussed above impacts on practitioner researchers' actions in WAL at the individual, group and organisational levels. There is some overlap and some integration of theoretical conceptualisation and practical application, but these theories all inform the participatory paradigms of WAL and action leadership. Through WAL, practitioner researchers use participatory action research and collaborative lifelong action learning in team projects aimed at practical improvement, positive social change and justice, for the common good of the organisation. Through action leadership, practitioner researchers share leadership assumed by whomever in the team is the best and first among equals for each particular task, purpose and responsibility, to achieve the best 
outcomes for all.

Table 1. Some theories embedded in practitioner researchers' actions (adapted from Zuber-Skerritt et al., 2015, p. 19)

\begin{tabular}{l|l}
\hline Theory & Practitioner Researchers' Actions \\
\hline Phenomenology & $\begin{array}{l}\text { Practitioner researchers conduct research into } \\
\text { phenomena/issues in their workplace/organisation } \\
\text { from their own experience and perspectives }\end{array}$ \\
\hline Experiential learning theory & $\begin{array}{l}\text { They gain understanding of work/life/change } \\
\text { processes and create knowledge based on reflecting } \\
\text { critically on their projects and experiences }\end{array}$ \\
\hline Strengths-based theory & $\begin{array}{l}\text { They identify and build on each team member's } \\
\text { strengths for maximum effectiveness and results at } \\
\text { the personal, professional, community or } \\
\text { organisational levels. }\end{array}$ \\
\hline Critical theory & $\begin{array}{l}\text { They collect, analyse and interpret action research } \\
\text { data to elicit the main categories, constructs, concepts } \\
\text { and principles from which grounded theory can } \\
\text { emerge, related to the issue(s)/theme of the research } \\
\text { project theory }\end{array}$ \\
$\begin{array}{l}\text { They use dialogue, dialectics, critical reflection, self- } \\
\text { reflection and meta-reflection to change their praxis, } \\
\text { their understanding of praxis, and if necessary, the } \\
\text { conditions/boundaries that constrain, inhibit or } \\
\text { prevent any improvement or change. }\end{array}$ \\
\hline
\end{tabular}

These theories listed in Table 1 provide a combined theoretical, pedagogical and methodological rationalisation of why the WAL model is an appropriate and effective approach to developing managers as professional, lifelong learners and practitioner researchers. Developed as such, they are best positioned to meet current and future requirements of the twenty-first century.

Figure 2 presents a summary of the WAL conceptual framework within the participatory paradigm. It requires participatory pathways and the integration of the three core WAL activities of managers: (1) action learning (AL), (2) action research (AR), and (3) organisation development/change (OD). This can be achieved through the seven C's (critical reflection, competence, coaching/mentoring, communication, collaboration, compromise and commitment) and the three R's (relationships, reflection and recognition/award) of WAL and PALAR. One of the important outcomes is action leadership, which enhances and strengthens praxis (i.e., integrated theory and practice). 


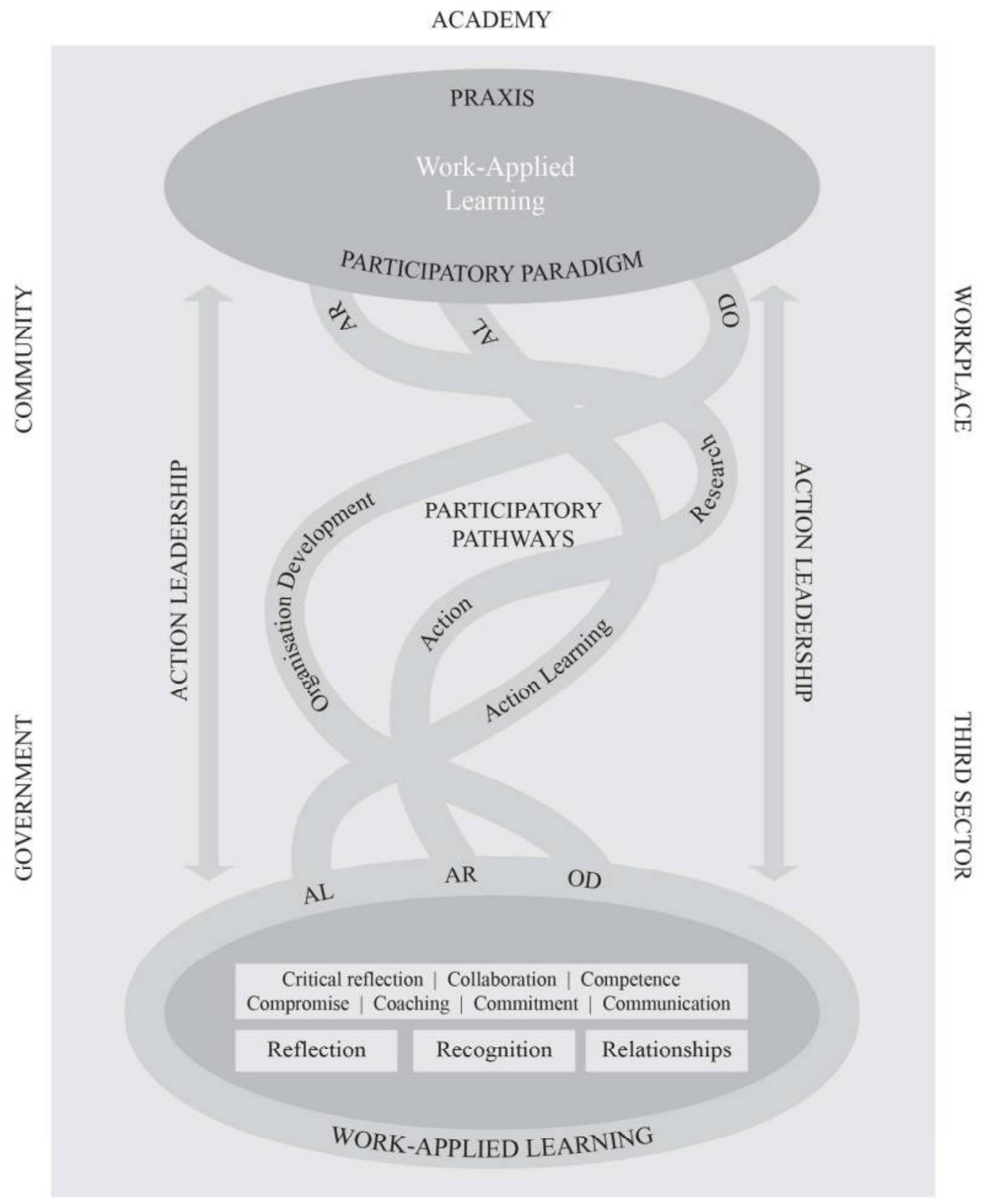

Figure 2. Conceptual framework of integrating action learning, action research and organisation development in the WAL model

(adapted from Zuber-Skerritt et al., 2015, p. 21)

This framework illustrates WAL as an integrated, inclusive approach to action and learning, research, and organisation development/change. It makes clear that workapplied learning is not confined within the classroom, but also takes place in the workplace (e.g., family enterprises, small, medium and large businesses and corporations, in government (i.e., at national and subnational levels), in the third sector (i.e., faith-based, non-government and other organisations), and in the wider community (including local, remote and disadvantaged communities). And of course, 
work-applied learning takes place in the academy - the Australian Institute of Business (AIB) and the Global Centre for Work-Applied Learning (GCWAL) in Adelaide, both focus on this type of learning - and in other institutions of management and higher education, such as GULL - the Global University for Lifelong Learning. Many of these sites of work-applied learning also forge close links with international networks through partnerships and other relationships across national borders.

\section{Conclusion}

This article aimed to clarify and justify Abraham's (2015) WAL model (summarised in Figure 1) theoretically, pedagogically and methodologically. Therefore, we first explained the work-applied learning model as practised in several organisations, particularly AIB (http://www.aib.edu.au), GCWAL (http://gcwal.com.au) and GULL (http://www.gullonline.org). Second, we explained the key concepts that are integrated within WAL - work-based learning, action research and action learning, reflective practice, organisational learning, lifelong learning and action leadership and explained why this model is especially appropriate for developing managers' knowledge and skills to cope with so-called wicked problems in the twenty-first century. Third, we offered a theoretical, pedagogical and methodological justification of the WAL model. Practical implications include that being based on this conceptual framework, managers/graduates as practitioner researchers can subsequently apply or adapt the model through empirical research and case studies in their own work contexts and by consulting Abraham's (2015) practical guidebook with case studies. Through this practical experience and the insights gained, they are likely to develop action leadership and be able to effectively steer their community or organisation into an uncertain future. The framework also helps ensure that research development is more responsive to the complex needs of our socio-cultural, economic and political contexts.

There are no fast steps or hard rules for developing action leadership through WAL. All contexts are distinctive as are all groups of practitioner researchers in their concerns, needs, interests, abilities, and motivations to learn and change. That is why active participation, collaboration and critical reflection in, on, after and for action are important in the WAL paradigm. It is also why WAL, ARAL and action leadership cannot be narrowly defined and will always be emergent concepts. As demonstrated by Zuber-Skerritt (2011) in the areas of higher education, and management education for organisation development and community development, work-applied learners and action researchers are able to develop as ethical, entrepreneurial action leaders in all sections of society, such as the workplace in organisations, communities, government, the third sector, and in the management education academy, as illustrated in Figure 2. They are able to act effectively and responsibly, observe and reflect critically and self-critically, and - on the basis of their experience and reflective practice - create new knowledge through ARAL that is contextual and relevant to their own and their organisations' development. In this way they are better positioned to work for a future world characterised by equal opportunity, social, economic and political justice, prosperity and openings for creative thinking and innovative acting. These learning and organisational outcomes have been confirmed and substantiated in the literature, for example by Coghlan and 
Brydon-Miller (2014) and the Sage Handbooks on Action Research (Reason and Bradbury, 2001, 2006, 2008, 2013; Bradbury, 2015).

Some people may see a difference between traditional, lecturer-centred and disciplinary-oriented management education and development versus a more action-, problem-, process- and future-oriented interdisciplinary approach to leadership development. The WAL model integrates both - the former approach through the 'knowledge workshop phase' and the latter in the 'AR group meetings', the 'workbased phase', the 'joint observations and reflections', and simultaneously through the 'evaluation of cycles' and 'validation of the WAL program'.

Our discussion here has been limited by the restrictions upon a journal article. These also preclude us from providing a practical guide for both managers as practitioner researchers and their educators on how to learn and how to become more effective WAL practitioners, action researchers and action leaders. We are considering this as the topic of a future publication and will accept readers' offerings that may contribute usefully to it. We also refer readers to published work listed in the 'References' below for further understanding. Meantime the conceptual framework we have presented in the present article outlines and concisely underscores the strengths of the WAL model as an effective, practical approach to management education, research and development for present and future requirements, while advancing an incipient literature on WAL by practitioner researchers as action leaders. Finally, we invite and encourage readers to conduct their own practitioner research to test and extend the conceptual framework we have introduced in this discussion.

\section{References}

Abraham, S. (Ed.) (2015), Work-applied Learning for Change, GCWAL Publications Pty Ltd, Adelaide.

Adorno, T. (2008), Lectures on Negative Dialectics, Polity, Cambridge.

Aspin, D., Chapman, J., Hatton, M. and Sawano, Y. (Eds) (2001), International Handbook of Lifelong Learning, Vol. 1 and 2, Kluwer Academic Publishers, Dordrecht, The Netherlands.

Bhaskar, R. (2008), A Realist Theory of Science, Verso, London (first published in 1975).

Biggs, J. (2005), Teaching for Quality Learning at University, 2nd ed., SRHE and Open University Press, Maidenhead.

Billet, S. (2010), "The perils of confusing lifelong learning with lifelong education", International Journal of Lifelong Learning, Vol. 29 No. 4, pp. 401-418.

Boud, D., Keogh, R. and Walker, D. (1985), Reflection: Turning Experience into Learning, Routledge, London.

Boud, D. and Solomon, N. (Eds) (2001), Work-based Learning: A New Higher Education? Open University Press, Buckingham, UK.

Bawden, R., \& Williams, M. (in press). The learning conference and worldview transformations. In O. Zuber-Skerritt (Ed.), Conferences as sites of learning and development: Using participatory action learning and action research approaches. London: Routledge.

Bradbury, H. (Ed.) (2015). The Sage hanbook of action research (3rd ed.). London: 
Sage.

Bryant, A. and Charmaz, K. (Eds) (2007), The Sage Handbook of Grounded Theory, Sage, Thousand Oaks, CA.

Burns, D. (2007, reprinted 2014), Systemic Action Research: A Strategy for Whole System Change, Policy Press, Bristol, UK.

Cantwell, J. (2015), Leadership in Action, Melbourne University Publishers, Melbourne.

Carr, W. and Kemmis, S. (1986). Becoming Critical: Education, Knowledge and Action Research, Falmer Press, London.

Charmaz, K. (2006), Constructing Grounded Theory: A Practical Guide through Qualitative Analysis, Sage, London.

Coghlan, D., \& Brydon-Miller, M. (Eds.) (2014), The Sage Encyclopedia of Action Research, Sage, London.

Corbin, J. and Strauss, A. (2013), Basics of Qualitative Research: Techniques and Procedures for Developing Grounded Theory, 4th ed., Sage, Thousand Oaks, CA.

Dahlberg, L. and McCraig, C. (Eds.) (2010), Practical Research and Evaluation: A Start-to-finish Guide for Practitioners, Sage, London.

Dick, B. (2012), "Action research and action learning for an uncertain and turbulent world", in O. Zuber-Skerritt (Ed.), Action Research for Sustainable

Development in a Turbulent World, Emerald Group Publishing Limited, Bingley, UK, pp. 29-44.

Drake, P. and Heath, L. (2011), Practitioner Research at Doctoral Level: Developing Coherent Research Methodologies, Routledge, Abington.

Fox, M., Martin, P. and Green, G. (2007), Doing Practitioner Research, Sage, London.

Garnett, J. (2012), “Authentic work-integrated learning”, in L. Hunt and D. Chalmers (Eds.), University Teaching in Focus: A Learning-centred Approach, ACER Press, Victoria, Australia, pp. 164-179.

Gibbs, G. and Garnett, J. (2007), "Work-based learning as a field of study", Research in Post-compulsory Education, Vol. 12 No 3, 409-421.

Gibson, B. and Hartman, J. (2013), Rediscovering Grounded Theory, Left Coast Press, Walnut Creek, CA.

Glaser, B., and Strauss, A. (1967), The Discovery of Grounded Theory: Strategies for Qualitative Research, Aldine, New York.

Godin, S. (2008), Tribes: We Need You to Lead, Penguin, London.

Greenwood, D. (2012). Reflective practice: A critique of the work of Argyris and Schön. Journal of Advanced Nursing, 18(8), 1183-1187.

Habermas, J. (1974), Theory and Practice, Heinemann, London.

Habermas, J. (1978), Knowledge and Human Interest, 2nd ed., Heinemann, London.

Harvey, M. (2014), "Strengths-based approach", in D. Coghlan and M. BrydonMiller (Eds.), The Sage Encyclopedia of Action Research, Vol. 2, Sage, London, pp. 732-735.

Jackson, S. (Ed.) (2011), Lifelong Learning and Social Justice: Communities, Work and Identities in a Globalised World, NIACE, Leicester, UK.

Jarvis, P. (Ed.) (2001). The Routledge International Handbook of Lifelong Learning. London: Routledge. 
Kemmis, S., McTaggart, R. and Nixon, R. (2014), The Action Research Planner: Doing Critical Participatory Action Research, Springer, Singapore.

Knott, C., and Scragg, T. (2011), Reflective Practice in Social Work(2nd ed.), Learning Matters, Exeter.

Kolb, D. (1984), Experiential Learning: Experience as the Source of Learning and Development, Prentice Hall, New Jersey.

Kuhn, T. S. (1970), The Structure of Scientific Revolutions, 2nd ed., The University of Chicago Press, Chicago.

Lewin, K. (1926), Vorsatz, Wille und Bedürfnis (Intention, Will and Need), Springer, Berlin.

Lewin, K. (1948), Resolving Social Conflict: Selected Papers on Group Dynamics, Harper and Brothers, New York.

Lewin, K. (1951), Field Theory in Social Science: Selected Theoretical Papers, Harper and Row, New York.

Maxwell, J. C. (1995), Developing the Leaders Around You: How to Help Others Reach their Full Potential, Thomas Nelson Publishers, Nashville, USA.

McCashen, W. (2005), The Strength Approach: A Strength-based Resource for Sharing Power and Creating Change, St Luke's Innovative Resources, Bendigo, Victoria, Australia.

Moon, J. (2006), Learning Journals: A Handbook for Reflective Practice and Professional Development (2nd ed.), Routledge, London.

Reason, P., \& Bradbury, H. (2001). Introduction: Inquiry and participation in search of a world view worthy of human aspiration. In P. Reason \& H. Bradbury (Eds.), Handbook of action research: Participatory inquiry and practice (pp. 1-14). London: Sage.

Reason, P., \& Bradbury, H. (Eds.). (2006). Handbook of Action Research: Concise Paperback Edition. London: Sage.

Reason, P., \& Bradbury, H. (Eds.). (2008). The Sage Handbook of Action Research: Participative Inquiry and Practice (2nd ed.). London: Sage.

Reason, P., \& Bradbury, H. (Eds.). (2013). The Sage Handbook of Action Research: Participatory Inquiry and Practice (3rd ed.). London: Sage.

Revans, R. (1971), Developing Effective Managers: A New Approach to Business Education, Longmans, London.

Revans, R. (1982), The Origins and Growth of Action Learning, Chartwell-Bratt, Bromley.

Revans, R. (1991), "The concept, origin and growth of action learning”, in O. ZuberSkerritt (Ed.), Action Learning for Improved Performance, AEBIS Publishing, Brisbane, pp. 14-25.

Revans, R. (1998), ABC of Action Learning: Empowering Managers to Act to Learn from Action, 3rd ed. Lemos and Crane, London.

Revans, R. (2006), Action Learning: Reg Revans in Australia, DVD, based on the video program produced by Ortrun Zuber-Skerritt in 1991. Video Vision, ITS, University of Queensland, Brisbane.

Saleebey, D. (2005), The Strength Perspective in Social Work Practice, 4th ed., Allyn and Bacon, Boston, MA.

Schön, D. A. (1983), The Reflective Practitioner: How Professionals Think in Action, Temple Smith, London. 
Schön, D. A. (1987), Educating the Reflective Practitioner, Jossey-Bass, San Francisco.

Senge, P. (1990), The Fifth Discipline: The Art and Practice of the Learning Organisation. Doubleday, New York.

Sheehan, P. (2001), "Foreword", in D. Aspin, J. Chapman, M. Hatton and Y. Sawano (Eds.), International Handbook of Lifelong Learning, Vol. 1, Kluwer Academic Publishers, Dordrecht, The Netherlands, pp. xi-xii.

Smith, D. W. (2013), "Phenomenology", in E. N. Zalta (Ed.), The Stanford Encyclopedia of Philosophy, Stanford: Available at:

http://plato.stanford.edu/archives/win2013/entries/phenomenology/.

Taylor, B. (2000), Reflective Practice, Open University Press, Buckingham.

Trilling, B., and Fadel, C. (2009), 21st Century Skills: Learning for Life in Our Times, Jossey-Bass, San Fransisco, CA.

Van Manen, M. (2014), Phenomenology of Practice: Meaning-giving Methods in Phenomenological Research and Writing, Left Coast Press, Walnut Creek, CA.

Yin, R. K. (2013), Case Study Research: Design and Methods, 5th ed., Sage, London.

Zohavi, D. (2003), Husserl's Phenomenology, Stanford University Press, Stanford.

Zuber-Skerritt, O. (2002a), "The concept of action learning," The Learning Organisation, Vol. 9 No 3, pp. 114-124.

Zuber-Skerritt, O. (2002b), "The concept of action research", The Learning Organisation, Vol. 9 No 3, pp. 125-131.

Zuber-Skerritt, O. (2009), Action Learning and Action Research: Songlines through Interviews, Sense Publishers, Rotterdam.

Zuber-Skerritt, O. (2011). Action Leadership: Towards a Participatory Paradigm, Springer, Dordrecht, The Netherlands.

Zuber-Skerritt, O., \& Teare, R. (2013). Lifelong Action Learning for Community Development: Learning and Development for a Better World. Rotterdam: Sense Publishers.

Zuber-Skerritt, O., Wood, L., and Louw, I. (2015), A Participatory Paradigm for an Engaged Scholarship in Higher Education: Action Leadership from a South African Perspective, Sense, Rotterdam.

\section{Note}

${ }^{1}$ Here we briefly summarise the essence and adapt Table 1 and Figure 1 of the conceptual framework for PALAR from Zuber-Skerritt, Wood and Louw (2015, pp. 13-21) in the sections on 'paradigm' and 'theories of knowing and learning', with permission of the authors and Sense Publishers (by emails of 5 and 6 March 2016). 